\title{
Ecohydrologic Implications of Deeply Rooted Grasses
}

\author{
Erik Oerter ${ }^{1 *}$, Erin Nuccio ${ }^{1}$, Eric Slessarev ${ }^{1}$, Kyungjin \\ Min $^{2}$, Megan Kan ${ }^{1}$, Ate Visser ${ }^{1}$, Karis McFarlane ${ }^{1}$, \\ Asmeret Asefaw Berhe ${ }^{2}$, Jennifer Pett-Ridge ${ }^{1}$ \\ ${ }^{1}$ Lawrence Livermore National Laboratory, CA 94550, USA, \\ *oerter1@LLNL.gov \\ ${ }^{2}$ University of California, Merced, CA 95343, USA.
}

Perennial crops with deep ( $>1 \mathrm{~m}$ ) rooting systems, such as switchgrass are hypothesized to increase the amount of carbon stored in the deep soil and may have the potential to facilitate long-term storage of this carbon. In addition to increasing belowground $\mathrm{C}$ inputs, deeply rooted plants can influence soil hydrology by accessing deep soil water. This, in turn, may alter regional hydrology because deep soil water is a source for groundwater recharge. We assessed the soil water content and stable isotopic compositions $\left(\delta^{2} \mathrm{H}\right.$ and $\delta^{18} \mathrm{O}$ values) of the water at detailed depth intervals to $>2.5 \mathrm{~m}$ soil depth at three sites in the southern Great Plains of North America. Results from these sites show distinct soil water content and stable isotope compositions throughout the depth profiles: soils under switchgrass were $5-10 \%$ wetter, with soil water Line-Conditioned Excess values (calculated from $\delta^{2} \mathrm{H}$ and $\left.\delta^{18} \mathrm{O}\right) 1-5 \%$ higher than that under shallow-rooted annual crops. Employing a Bayesian mixing model, we demonstrate that the proportions of source waters were similar at these sites, with winter precipitation dominating. To explain the soil water observations, we consider and discuss the potential mechanisms of: (1) preferential evaporation and mixing of antecedent soil water, and (2) potential hydraulic redistribution and deep soil water lift by switchgrass. These results indicate that deeply rooted switchgrass crops may have distinct ecohydrologic effects on their ecosystems, which may manifest as potentially enhanced evapotranspiration flux, as well as changes to groundwater recharge. Thus, in addition to altering ecosystem $\mathrm{C}$ balance, cultivation of deeply rooted perennial crops may influence the local water cycle. 